\title{
KNOWLEDGE MANAGEMENT AND FINANCIAL PERFORMANCE IN TRANSITIONAL ECONOMIES: THE CASE OF SERBIAN ENTERPRISES
}

\author{
Mila KAVALIĆ(D) ${ }^{*}$, Milan NIKOLIĆ ${ }^{2}$, Sanja STANISAVLJEV (D2,

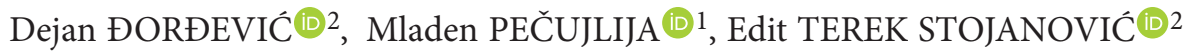 \\ ${ }^{1}$ Department of Industrial Engineering and Management, \\ Faculty of Technical Science, University of Novi Sad, Novi Sad, Serbia \\ ${ }^{2}$ Department of Management, Technical Faculty "Mihajlo Pupin", \\ University of Novi Sad, Zrenjanin, Serbia
}

Received 02 October 2020; accepted 21 June 2021

\begin{abstract}
In this paper the impact and predictive effects of knowledge management on financial performance are analysed. The research also includes an analysis of the moderating effects of two moderators (National Origin and Enterprise Size) and their relationship. The data was gathered by interviewing 520 managers from manufacturing companies operating in Serbia. The most important conclusions of the research are: 1 . High levels of knowledge management positively influence business performance, quality and competitiveness. 2 . Financial performance is mainly influenced by the dimensions connected to the effects of knowledge management regarding its implementation and protection and the acquisition of competitive advantages. 3. Knowledge management strongly influences the market aspects of business, but also the increase of fixed assets. 4. Knowledge management has a slightly greater impact on financial performance in foreign enterprises (operating in Serbia) compared to domestic (Serbian) enterprises. The situation is similar when comparing medium and large enterprises (a higher impact) with small enterprises (a smaller impact). 5. The greatest effects are achieved when an effective organizational structure is in place, when the organization protects its knowledge, when it manages to materialize the knowledge gathered in the form of the efficient application of knowledge.
\end{abstract}

Keywords: knowledge management, intellectual capital, financial performance, national origin of the enterprise, enterprises size, Serbia.

JEL Classification: M00, M20, A12, F63, L21.

\section{Introduction}

In today's economy, characterized by dynamic changes and business challenges, it is crucial for organizations to develop knowledge-based strategies in order to achieve a competitive advan-

${ }^{\star}$ Corresponding author. E-mail: mila@tfzr.uns.ac.rs

Copyright (c) 2021 The Author(s). Published by Vilnius Gediminas Technical University

This is an Open Access article distributed under the terms of the Creative Commons Attribution License (http://creativecommons. org/licenses/by/4.0/), which permits unrestricted use, distribution, and reproduction in any medium, provided the original author and source are credited. 
tage on the market. In this way, by knowledge management concept, companies successfully make preparations to cope with demanding and chaotic business circumstances. The responsibility of the knowledge management program is in the need that organizations and individuals get collective knowledge by persistent learning and improvement. The characteristics of human resources (socio-demographic and psychological) and those of the companies where employees work play a large role in the implementation of knowledge management programs in enterprises. Knowledge management affects various business aspects of the organization.

According to Crema and Verbano (2016), Xu and Wang (2018), Tonial et al. (2019), Gross-Golacka et al. (2020), in the knowledge economy, specialists and intellectuals came to a conclusion that intellectual capital (IC) can be the main driving force of sustainability and competitiveness. Furthermore, Xu and Wang (2018) and also Hermawan et al. (2020) came to a conclusion that IC investment plays a central function in companies that want to secure a sustainable competitive dominance.

Knowledge generates income in different ways. It can be in the form of good marketing, good design, satisfied customers, and improved production methods. Businesses can build success with greater expertise than their competitors. Knowledge that is constantly updated and improved is the primary source of competitive advantage. Enterprises in the knowledge era must constantly learn. The only way to stay on top is to learn faster and better than their competitors (Martin, 1998). The concept of knowledge management is the ability to access information that will allow anyone in the organization to make the best decision in a relatively short time, regardless of the business metric. Such metrics may be market conditions, products, services, processes, planned activities of competitors or other information relevant for the financial success of the enterprise (Shockley, 2000). By developing intellectual potential, a new competitive weapon is created for a new economy where knowledge is the main product. The ability to manage knowledge is becoming increasingly important in today's knowledge economy. The creation and dissemination of knowledge within a modern organization is becoming a decisive factor in achieving and sustaining competitiveness on the market (Davenport \& Prusak, 2000). In fact, the only sustainable advantage of a modern organization comes from what the enterprise knows, how effectively it uses what it knows, and how quickly it acquires and uses new knowledge.

Intellectual capital consists of the know-how of the human resources of a company. The experience and expertise of employees which may serve to improve organizational performance make the human capital of a company (Dzenopoljac et al., 2017; Allameh, 2018; Xu \& Wang, 2018). According to Jordão and de Almeida (2017), Xu and Wang (2018), Xu and Liu (2020), the intellectual capital - financial performance connection is the main centre of attention of researchers. Abdi et al. (2018) have concluded that recognizing and measuring the value of organizational knowledge is very hard for researchers. If a companies value is in the intellectual capital, rather than in conventional resources, it is crucial to create consciousness of the management of a company about this question (Bontis et al., 1999). According to Sharma and Dharni (2017), Dzenopoljac et al. (2017), Ferramosca and Ghio (2018), Xu and Li (2019), Xu and Liu (2020), in emerging economies surveying the function of intellectual capital is a problem and further study is needed. Intellectual capital may provide better financial performance for a company (Xu \& Liu, 2021). 
There are many academic papers that deal with the issue between knowledge management and various organizational outcomes. Knowledge management increases the competitiveness and development of a company (Echeverry et al., 2019), while on a macro level they contribute to economic growth (Sanchez, 2018). Different knowledge management components, models, and procedures mean also improving business performance (Zebal et al., 2019; Dang et al., 2018; Lee et al., 2005).

The application of knowledge management in a right manner can enhance the financial performance of organizations (Mageswari et al., 2017; Razzaq et al., 2019; Najmi et al., 2018; Chen \& Huang, 2009; Lee et al., 2008). Similarly, human resource progress, noticeable learning capability, and also managing of intellectual capital in a right way, all positively affect financial performance (Mondal \& Ghosh, 2012; Maditinos et al., 2011; Prieto \& Revilla, 2006; Joshi et al., 2013; Kianto et al., 2013; Fathi et al., 2013).

Previous considerations indicate that knowledge management has significant effects on an organization's financial performance. However, in previously conducted studies the observed relations were not analyzed in detail or in depth, in terms of discovering and explaining the impact of individual dimensions of knowledge management on individual items of financial performance. The study presented in this paper aims at examining and describing the relationship between knowledge management and financial indicators in organizations. Compared to other studies, the one presented in this paper focuses on the individual influences of the nine dimensions of knowledge management on the seven items of financial performance. This facilitates both an accurate and detailed observation and a deeper understanding of the connections between different segments of knowledge management and their financial effects in organizations.

In addition, in the analysis of the observed relations, two moderators are introduced (the national origin of the enterprise and enterprise size). These moderators are used because they affect knowledge management implementation, and thus also influence the relation between knowledge management and financial performance. The analysis of these moderating effects provides additional, even deeper insight into the nature of the observed relations, which, as already mentioned, are already observed in detail in this paper.

It should also be emphasized that, thanks to the results presented in this paper, the influences of knowledge management on the enterprises' financial performance were analyzed for the first time in the specific, transitional conditions, which are present in Serbia. Overall, there is a lack of studies in the existing body of literature dealing with the influence of knowledge management on financial performance in a transitional setting, and the number of studies falls even further when the moderating effects of national origin and enterprise size are introduced.

Therefore, this research setting provides the possibility for a detailed and in-depth understanding of the effects of knowledge management (including individual aspects) on financial performance in enterprises. The influence of the moderators contributes to the overall research setting. The research provides results that are derived from transitional conditions, and there is a possibility for meta-analysis and a comparison with other studies conducted in both other developing countries and more developed ones.

In addition to the theoretical significance, which was previously described, this research also has a pronounced practical significance. Namely, it traces the direction in which the 
implementation of knowledge management can maximize financial performance. Detailed knowledge on the observed relations provides greater insight about the methods/program for upgrading knowledge management in Serbian enterprises, and in turn the financial performance of these organizations. This kind of knowledge is very important for the Serbian economy. Specifically, based on the obtained results and performed analyzes, guidelines and recommendations for leaders and managers of Serbian enterprises have been defined. The proposals are focused on how to increase the financial performance of the enterprise through the application and improvement of knowledge management. The obtained results and recommendations for improvement are valid for the conditions of the subject of research (Serbian enterprises), but they can easily be used alike basically in countries in transition. At the same time, there is always the possibility of carrying out similar studies with different sample structures. The noted guidelines create better conditions for knowledge management implementation and increasing the level of financial indicators. In this way, this current research contributes to the expansion of both theoretical and practical knowledge in the field of knowledge management application and its effects.

This paper includes four main sections (excluding the introduction and conclusion). In the introduction the research problem analysing the impact of financial performance on knowledge management is addressed. The first section provides a thorough literature review in order to form a theoretical background for the research. In this section knowledge management and the enterprises' financial performance are analyzed, two hypotheses are introduced, and two research questions are proposed. The second section presents the research methodology and provides more details on the research instruments (survey), sample size and structure, and elaborates the data collection process. Then, the research results are presented in the third section, including the descriptive statistics, correlation analysis, regression analysis, and the analysis of the moderating effects which are present in the observed relations. In the next section, the research results are discussed in more detail. In the end, based on the obtained research results, the conclusions are drawn and suggestions for future research are proposed.

\section{Theory and hypothesis}

\subsection{Knowledge management}

Knowledge management helps companies to evolve strategic capabilities concerning uncertainty (Nguyen, 2010). Knowledge management can be defined as "an organizational ability that identifies, locates (creates or acquires), transmits, transforms and distributes knowledge into competitive advantage" (Walters, 2002, p. 7). Massa and Testa (2009, p. 131) stated that knowledge management is "a process that involves the acquisition and creation of knowledge; as well as obtaining, storing and retrieving knowledge; the dissemination, transfer and sharing of knowledge; and the application of knowledge by organizations in order to improve their competitive advantage". Similarly, according to the American Productivity and Quality Center [APQC] (1998), knowledge management is a management discipline that refers to the systematic acquisition, creation, sharing and use of knowledge in organizations, with the aim of improving the competitiveness of enterprises through continuous and rapid innova- 
tion. The influence of knowledge management on competitive advantage is also advocated by other authors such as Kongpichayanond (2009).

Darroch and McNaughton (2002) presented knowledge management as a management function that creates, locates, and manages the flow of knowledge within an organization, to ensure that knowledge is effectively and efficiently used in order to achieve long-term benefits for the organization. This is further supported by James (2005, p. 51), who noted that knowledge management is "the identification, acquisition, use, support, maintenance and disposal of knowledge assets for the purpose of adding value and benefit to all stakeholders". Most published works deal with this issue of Western or Asian countries. There are just few researches about less developed economies (Nguyen, 2010).

The previous definitions clearly argue in favour ofthe importance of knowledge management for businesses and business perfromance. In terms of achieving competitiveness, systematic and effective knowledge management application certainly ensures long-term benefits and the continuous development of organizations.

\subsection{Financial performance}

The main and final goal of organizational activities is business success, which is measured through performance metrics. Organizational performance is the ability to acquire financial and physical resources in an appropriate manner, in order to achieve organizational goals (Madella et al., 2005). Therefore, it can be argued that organizational performance is an indicator of meeting organizational goals. According to Lee (2008), organizational performance is the result of organizational functions, and is measured through the degree of achievement of organizational goals. Schermerhorn, Hunt, and Osborn (2002) indicated that performance is related to the quality and quantity of accomplishment of the planned tasks of an individual or group of employees.

Financial indicators are the most used variables in measuring the business performance of companies, signaling the financial position, comprehensive income, and other significant reporting aspects (Sabău Popa et al., 2021). Organizational performance includes financial and non-financial dimensions (Ouekouak et al., 2014). Hence, it is very useful and important to observe all the factors that affect enterprises' financial performance. Business performance is reflected in financial indicators. Some of those financial indicators include: productivity, profitability, market share, sales growth, competitiveness, and fixed assets (Tan \& Litschert, 1994; Wang et al., 2003, 2011).

\subsection{Knowledge management and financial performance}

Knowledge management is a significant source of competitive strength for organizations, and it can result in numerous business benefits. Knowledge management is currently considered to be a key factor for organizational development, competitive business dynamics and productivity improvement (Echeverry et al., 2019). Zebal, Ferdous, and Chambers (2019) developed a conceptual model that integrates internal, tacit and explicit knowledge perspectives, thus ensuring greater business success. A link exists between economic growth and public expenditure, investment, human capital, knowledge and entrepreneurship (Sanchez, 2018). 
Knowledge enabling factors have a significant impact on organizational effectiveness outcomes (Dang et al., 2018). Also, the knowledge circulation process influences financial performance and indicates positive business results (Lee et al., 2005). Darroch (2005) suggests that companies with good knowledge managing have more efficiency in using resources, innovativeness is on a high level so they reach better financial results. Likewise, organizational learning has a positive effect on innovation, competitiveness and financial results (Lopez et al., 2005).

The implementation of knowledge management directly influences the improvement of a company's financial performance. This was also noted by Mageswari, Sivasubramanian, and Dath (2017), who observed that the acceptance and usage of knowledge management leads to better financial performance of organizations. The functions of KM address the problem of low organizational commitment, that also results in improved financial performance (Razzaq et al., 2019). The supporting results obtained by Chen and Huang (2009) also indicate that knowledge mnanaging in a right manner is very important between HR and financial performance. Similarly, knowledge management was found to have an impact on the financial performance of SMEs (Lee et al., 2008).

Intellectual capital performance impacts on financial performance indicators (Mondal \& Ghosh, 2012). Similarly, according to (Maditinos et al., 2011), there is a statistically significant relationship between the efficiency of human capital and the financial performance of enterprises. Improvement of HR is of crucial importance for economic success and human capital should be one of the companies' main focus points. A positive link exists between financial performance and learning ability (Prieto \& Revilla, 2006). Furthermore, KM and the enhancement of intellectual capital positively affect the maximization process of financial values (Joshi et al., 2013). Other studies, for example (Kianto et al., 2013; Fathi et al., 2013), also speak about the effects of intellectual capital on an organization's financial performance.

Contrary to the aforementioned findings, different results were obtained in the study conducted by Zack, McKeen, and Singh (2009), who did not find a direct correlation between knowledge management and financial performance. However, knowledge management practices are directly related to organizational performance, and organizational performance is in turn directly related to financial performance. This further indicates the indirect impact of knowledge management on financial performance (Zack et al., 2009).

Based on the noted findings, the paper proposes two hypotheses:

H1: Knowledge management dimensions are in a statistically significant correlation with the financial performance items and the financial performance dimension.

$\mathrm{H} 2$ : Knowledge management dimensions have a statistically significant predictive effect on the financial performance items and the financial performance dimension.

This paper also examines the moderating effect of National Origin of Enterprises and Enterprise Size within the observed relationships. Two research questions are set:

RQ1: Does the National Origin of Enterprises have a moderating effect on the relationship between the dimensions of knowledge management and the financial performance items (and the financial performance dimension)?

RQ2: Does Enterprise Size have a moderating effect on the relationship between the dimensions of knowledge management and the financial performance items (and the financial performance dimension)? 


\section{Method}

\subsection{Instruments used in the survey}

Knowledge management. The instrument measuring knowledge management by Nguyen (2010) was used in this research. It is modelled on standardized questionnaires for the individual fields of knowledge management, which have been consolidated into one questionnaire. The questionnaire gives a global score regarding the application of knowledge management through 50 items divided to 9 dimensions (Nguyen, 2010): KM1 - Organizational Structure, KM2 - Organizational Culture, KM3 - T-shaped Skills - Human Resources, KM4 - Information Technology, KM5 - Knowledge Acquisition Processes, KM6 - Knowledge Conversion Processes, KM7 - Knowledge Application Processes; KM8 - Knowledge Protection, KM9 - Competitive Advantage. The rating was done through a seven-point Likert scale.

Financial Performance. The financial performance items were selected based on other studies. The items are: FP2 - Profitability, FP3 - Market Share, FP4 - Sales Growth, FP5 Competitive Status in the firm's industry and FP6 - Asset Growth (Tan \& Litschert, 1994; Wang et al., 2003, 2011). In addition, two other items were added: FP1 - Productivity and FP7 - Salaries. A total of seven financial performance items were formed. The items were structured as seven-point Likert scales. This approach to evaluating financial performance has been applied in other similar studies (Tan \& Litschert, 1994; Wang et al., 2003, 2011), and was found to be adequate for this type of evaluation. These seven items form an integral part of the financial performance dimension.

\subsection{Sample structure and data collection}

The participants who completed anonymous questionnaires were managers at all levels, employed in manufacturing enterprises in Serbia. Managers are the ones who can in the best way oversee the knowledge management implementation, as well as the impact and predictive effects of knowledge management on financial performance. Managers of all levels were included, because in this way a full and real picture of the implementation of knowledge management is shown, as well as the effects of knowledge management on financial performance.

The sample was constructed in such a way as to include both domestic (Serbian) and foreign enterprises (operating in Serbia), companies of different sizes, as well as companies under different ownership structures. A total of $\mathrm{N}=520$ valid questionnaires were collected. In terms of national origin, the sample includes 372 domestic companies, and 148 foreign companies. The foreign companies are from: Australia, Croatia, Italy and Germany. When it comes to size of the company, there were included small companies (up to 50 employees) and medium and large companies (over 50 employees). There are 300 managers from small companies and 220 from medium and large companies. In terms of the ownership structure of the company, there were 99 state owned companies and 421 private companies. The industries were the companies belong to are: textile, chemical-food, and automotive. When it comes to the age of the respondents, the sample was divided into two groups: up to 45 
years of age and over 45 years of age. Those under the age up to 45 accounted for $64.8 \%$ of the respondents, while those over the age of 45 stood at $35.2 \%$. From the aspect of gender, it can be noticed that a similar percentage of male and female respondents participated in the research. Women had a slightly lower share of $44.8 \%$, while the percentage of male respondents was $55.2 \%$.

\subsection{Correlation analysis}

The correlation coefficients between the knowledge management dimensions and the financial performance items and dimension are given in Table 1. Pearson's correlation was conducted both for ${ }^{\star} \mathrm{p}<0.05$ and ${ }^{\star *} \mathrm{p}<0.01$.

Table 1. Correlation coefficients between the dimensions of knowledge management and the dimensions of financial performance (items) and the financial performance as a dimension

\begin{tabular}{|l|c|c|c|c|c|c|c|c|}
\hline & FP1 & FP2 & FP3 & FP4 & FP5 & FP6 & FP7 & FP \\
\hline KM1 & $.567^{* *}$ & $.234^{* *}$ & $.289^{* *}$ & $.335^{* *}$ & $.282^{* *}$ & $.357^{* *}$ & $.250^{* *}$ & $.393^{* *}$ \\
\hline KM2 & $.364^{* *}$ & $.243^{* *}$ & $.379^{* *}$ & $.335^{* *}$ & $.350^{* *}$ & $.345^{* *}$ & $.290^{* *}$ & $.388^{* *}$ \\
\hline KM3 & $.402^{* *}$ & $.262^{* *}$ & $.347^{* *}$ & $.391^{* *}$ & $.319^{* *}$ & $.407^{* *}$ & $.277^{* *}$ & $.404^{* *}$ \\
\hline KM4 & $.412^{* *}$ & $.314^{* *}$ & $.377^{* *}$ & $.390^{* *}$ & $.370^{* *}$ & $.381^{* *}$ & $.334^{* *}$ & $.432^{* *}$ \\
\hline KM5 & $.245^{* *}$ & $.391^{* *}$ & $.525^{* *}$ & $.473^{* *}$ & $.431^{* *}$ & $.433^{* *}$ & $.402^{* *}$ & $.482^{* *}$ \\
\hline KM6 & $.196^{* *}$ & $.358^{* *}$ & $.411^{* *}$ & $.427^{* *}$ & $.375^{* *}$ & $.405^{* *}$ & $.360^{* *}$ & $.420^{* *}$ \\
\hline KM7 & $.256^{* *}$ & $.431^{* *}$ & $.448^{* *}$ & $.540^{* *}$ & $.457^{* *}$ & $.451^{* *}$ & $.441^{* *}$ & $.501^{* *}$ \\
\hline KM8 & $.301^{* *}$ & $.398^{* *}$ & $.449^{* *}$ & $.439^{* *}$ & $.433^{* *}$ & $.574^{* *}$ & $.426^{* *}$ & $.502^{* *}$ \\
\hline KM9 & $.272^{* *}$ & $.464^{* *}$ & $.450^{* *}$ & $.485^{* *}$ & $.564^{* *}$ & $.445^{* *}$ & $.506^{* *}$ & $.527^{* *}$ \\
\hline
\end{tabular}

Note: ${ }^{\star}$ Author's research results.

\subsection{Regression analysis}

The predictive effect of the knowledge management dimensions as independent variables on the financial performance items and the financial performance dimension (dependent variables) was examined using multiple regression analysis. The results of the regression analysis are given in Table 2 . The statistically significant results which have a predictive effect are shown in bold font.

\subsection{The moderating effect of Enterprise Size}

The correlation analysis results among the knowledge management dimensions and the financial performance items and dimension are given separately for domestic and foreign companies in Table 3. The moderating effect of National Origin of Enterprises was tested using hierarchical regression analysis. In Table 3, the results where there is a moderating effect of the companies' National Origin are marked in bold font. 
Table 2. Regression analysis (independent variables: the knowledge management dimensions; dependent variables: the financial performance items and the financial performance dimension)

\begin{tabular}{|c|c|c|c|c|c|c|c|c|c|c|c|c|}
\hline \multicolumn{10}{|c|}{ Indep. } & \multirow{3}{*}{$\mathrm{R}^{2}$} & \multirow{3}{*}{$\mathrm{F}$} & \multirow{3}{*}{ Sig. } \\
\hline $\begin{array}{l}\text { De- } \\
\text { pend. }\end{array}$ & KM1 & KM2 & KM3 & KM4 & KM5 & KM6 & KM7 & KM8 & KM9 & & & \\
\hline & & & \\
\hline FP1 & 0.584 & -0.106 & 0.075 & 0.032 & 0.067 & -0.006 & -0.192 & 0.039 & 0.057 & 0.329 & 27.817 & 0.000 \\
\hline FP2 & 0.077 & -0.134 & -0.103 & 0.026 & -0.038 & 0.041 & 0.093 & 0.060 & 0.438 & 0.233 & 17.222 & 0.000 \\
\hline FP3 & -0.034 & 0.067 & -0.035 & 0.116 & 0.551 & -0.075 & -0.156 & 0.116 & 0.011 & 0.292 & 23.427 & 0.000 \\
\hline FP4 & 0.094 & -0.023 & -0.013 & 0.004 & -0.021 & -0.004 & 0.500 & -0.039 & 0.074 & 0.297 & 23.988 & 0.000 \\
\hline FP5 & 0.029 & -0.040 & -0.079 & 0.045 & -0.049 & -0.027 & -0.089 & 0.023 & 0.718 & 0.328 & 27.699 & 0.000 \\
\hline FP6 & 0.035 & -0.008 & 0.049 & 0.033 & -0.054 & -0.023 & -0.030 & 0.604 & -0.014 & 0.336 & 28.656 & 0.000 \\
\hline FP7 & 0.041 & -0.056 & -0.127 & 0.029 & -0.089 & -0.009 & 0.049 & 0.113 & 0.536 & 0.270 & 20.937 & 0.000 \\
\hline FP & 0.146 & -0.047 & -0.035 & 0.049 & 0.072 & -0.019 & 0.020 & 0.152 & 0.289 & 0.312 & 25.665 & 0.000 \\
\hline
\end{tabular}

Note: ${ }^{*}$ Author's research results

Table 3. Correlation coefficients between the dimensions of knowledge management and the dimensions of financial performance (items) and dimensions for domestic and foreign companies (observed separately)

\begin{tabular}{|c|c|c|c|c|c|c|c|c|c|}
\hline $\begin{array}{c}\text { National } \\
\text { origin }\end{array}$ & & FP1 & FP2 & FP3 & FP4 & FP5 & FP6 & FP7 & FP \\
\hline \multirow{9}{*}{ Domestic } & KM1 & $.584^{* *}$ & $.240^{* *}$ & $.254^{* *}$ & $.330^{* *}$ & $.290^{* *}$ & $.320^{\star *}$ & $.243^{* *}$ & $.387^{* *}$ \\
\hline & KM2 & $.359^{* *}$ & $.243^{* *}$ & $.360^{* *}$ & $.329^{* *}$ & $.358^{* *}$ & $.302^{* *}$ & $.285^{* *}$ & $.379^{* *}$ \\
\hline & KM3 & $.406^{* *}$ & $.253^{* *}$ & $.320^{* *}$ & $.408^{* *}$ & $.331^{* *}$ & $.383^{* *}$ & $.265^{* *}$ & $.401^{* *}$ \\
\hline & KM4 & $.435^{* *}$ & $.312^{* *}$ & $.360^{* *}$ & $.388^{* *}$ & $.383^{* *}$ & $.367^{* *}$ & $.318^{* *}$ & $.433^{* *}$ \\
\hline & KM5 & $.199^{* *}$ & $.422^{* *}$ & $.506^{* *}$ & $.485^{* *}$ & $.445^{* *}$ & $.418^{* *}$ & $.414^{* *}$ & $.482^{* *}$ \\
\hline & KM6 & $.155^{* *}$ & $.369^{* *}$ & $.402^{* *}$ & $.420^{* *}$ & $.369^{* *}$ & $.388^{* *}$ & $.359^{* *}$ & $.410^{* *}$ \\
\hline & KM7 & $.252^{* *}$ & $.435^{* *}$ & $.456^{* *}$ & $.555^{* *}$ & $.464^{* *}$ & $.460^{* *}$ & $.433^{* *}$ & $.510^{* *}$ \\
\hline & KM8 & $.270^{* *}$ & $.440^{* *}$ & $.424^{* *}$ & $.439^{* *}$ & $.443^{* *}$ & $.566^{* *}$ & $.443^{* *}$ & $.503^{* *}$ \\
\hline & KM9 & $.267^{* *}$ & $.490^{* *}$ & $.443^{* *}$ & $.487^{* *}$ & $.581^{* *}$ & $.445^{* *}$ & $.528^{* *}$ & $.539^{* *}$ \\
\hline \multirow{9}{*}{ Foreign } & KM1 & $.509^{* *}$ & $.244^{* *}$ & $.411^{* *}$ & $.347^{* *}$ & $.242^{* *}$ & $.453^{* *}$ & $.286^{* *}$ & $.411^{* *}$ \\
\hline & KM2 & $.368^{* *}$ & $.288^{* *}$ & $.464^{* *}$ & $.354^{* *}$ & $.308^{* *}$ & $.467^{* *}$ & $.332^{* *}$ & $.423^{* *}$ \\
\hline & KM3 & $.405^{* *}$ & $.277^{* *}$ & $.425^{* *}$ & $.351^{* *}$ & $.305^{* *}$ & $.485^{* *}$ & $.303^{* *}$ & $.418^{* *}$ \\
\hline & KM4 & $.329^{* *}$ & $.345^{* *}$ & $.441^{* *}$ & $.391^{* *}$ & $.322^{* *}$ & $.418^{* *}$ & $.395^{* *}$ & $.429^{* *}$ \\
\hline & KM5 & $.387^{* *}$ & $.304^{* *}$ & $.585^{* *}$ & $.435^{* *}$ & $.397^{* *}$ & $.476^{* *}$ & $.370^{* *}$ & $.483^{* *}$ \\
\hline & KM6 & $.329^{* *}$ & $.362^{* *}$ & $.457^{* *}$ & $.450^{* *}$ & $.386^{* *}$ & $.455^{* *}$ & $.390^{* *}$ & $.459^{* *}$ \\
\hline & KM7 & $.268^{* *}$ & $.432^{* *}$ & $.426^{* *}$ & $.477^{* *}$ & $.441^{* *}$ & $.435^{* *}$ & $.480^{* *}$ & $.476^{* *}$ \\
\hline & KM8 & $.382^{* *}$ & $.308^{* *}$ & $.536^{* *}$ & $.442^{* *}$ & $.394^{* *}$ & $.590^{* *}$ & $.396^{* *}$ & $.499^{* *}$ \\
\hline & KM9 & $.272^{* *}$ & $.427^{* *}$ & $.491^{* *}$ & $.479^{* *}$ & $.499^{* *}$ & $.438^{* *}$ & $.465^{* *}$ & $.495^{* *}$ \\
\hline
\end{tabular}

Note: ${ }^{*}$ Author's research results. 


\subsection{The moderating Effect of Enterprise Size on the observed relations}

The correlation analysis results among the knowledge management dimensions and the financial performance items and dimension separately presented for small companies and medium and large companies, are given in Table 4 . The test for the moderating effect of Enterprise Size was performed by applying hierarchical regression analysis. In Table 4, the results confirming the moderating effect of Enterprise Size are marked in bold font.

Table 4. Correlation coefficients between the dimensions of knowledge management and the dimensions of financial performance (items) and dimensions for small companies and medium and large companies (observed separately)

\begin{tabular}{|c|c|c|c|c|c|c|c|c|c|}
\hline $\begin{array}{l}\text { Enterprise } \\
\text { size }\end{array}$ & & FP1 & FP2 & FP3 & FP4 & FP5 & FP6 & FP7 & $\mathrm{FP}$ \\
\hline \multirow{9}{*}{ Small } & KM1 & $.593^{* *}$ & $.268^{* *}$ & $.245^{\star *}$ & $.341^{* *}$ & $.314^{* *}$ & $.334^{\star *}$ & $.274^{* *}$ & $.405^{* *}$ \\
\hline & KM2 & $.344^{* *}$ & $.258^{* *}$ & $.374^{* *}$ & $.335^{* *}$ & $.392^{* *}$ & $.282^{* *}$ & $.307^{* *}$ & $.388^{* *}$ \\
\hline & KM3 & $.436^{* *}$ & $.244^{* *}$ & $.281^{* *}$ & $.371^{* *}$ & $.321^{* *}$ & $.361^{* *}$ & $.253^{* *}$ & $.385^{* *}$ \\
\hline & KM4 & $.432^{* *}$ & $.285^{* *}$ & $.333^{* *}$ & $.366^{* *}$ & $.330^{* *}$ & $.319^{* *}$ & $.270^{* *}$ & $.397^{* *}$ \\
\hline & KM5 & $.165^{* *}$ & $.395^{* *}$ & $.497^{* *}$ & $.460^{* *}$ & $.406^{* *}$ & $.369^{* *}$ & $.383^{* *}$ & $.446^{* *}$ \\
\hline & KM6 & $.116^{*}$ & $.355^{* *}$ & $.387^{* *}$ & $.379^{* *}$ & $.325^{* *}$ & $.360^{* *}$ & $.339^{* *}$ & $.375^{* \star}$ \\
\hline & KM7 & $.244^{* *}$ & $.419^{* *}$ & $.426^{* *}$ & $.520^{* *}$ & $.422^{* *}$ & $.407^{* *}$ & $.403^{* *}$ & $.473^{* *}$ \\
\hline & KM8 & $.263^{* *}$ & $.417^{* *}$ & $.422^{* *}$ & $.419^{* *}$ & $.401^{* *}$ & $.543^{* *}$ & $.407^{* *}$ & $.478^{* *}$ \\
\hline & KM9 & $.265^{* *}$ & $.472^{* *}$ & $.455^{* *}$ & $.467^{* *}$ & $.553^{* *}$ & $.400^{* *}$ & $.499^{* *}$ & $.517^{* *}$ \\
\hline \multirow{9}{*}{$\begin{array}{l}\text { Medium } \\
\text { and large }\end{array}$} & KM1 & $.500^{* *}$ & $.221^{* *}$ & $.424^{* *}$ & $.374^{* *}$ & $.237^{* *}$ & $.409^{* *}$ & $.249^{* *}$ & $.399^{* *}$ \\
\hline & KM2 & $.375^{* *}$ & $.290^{* *}$ & $.454^{* *}$ & $.402^{* *}$ & $.301^{* *}$ & $.452^{* *}$ & $.317^{* *}$ & $.426^{* *}$ \\
\hline & KM3 & $.383^{* *}$ & $.276^{* *}$ & $.445^{* *}$ & $.412^{* *}$ & $.322^{* *}$ & $.472^{* *}$ & $.299^{* *}$ & $.430^{* *}$ \\
\hline & KM4 & $.371^{* *}$ & $.377^{* *}$ & $.467^{* *}$ & $.440^{* *}$ & $.435^{* *}$ & $.477^{* *}$ & $.444^{* *}$ & $.494^{* *}$ \\
\hline & KM5 & $.395^{* *}$ & $.391^{* *}$ & $.582^{* *}$ & $.500^{* *}$ & $.473^{* *}$ & $.533^{* *}$ & $.438^{* *}$ & $.544^{* *}$ \\
\hline & KM6 & $.344^{* *}$ & $.375^{* *}$ & $.463^{* *}$ & $.516^{* *}$ & $.455^{* *}$ & $.477^{* *}$ & $.402^{* *}$ & $.497^{* *}$ \\
\hline & KM7 & $.300^{* *}$ & $.441^{* *}$ & $.479^{* *}$ & $.563^{* *}$ & $.514^{* *}$ & $.523^{* *}$ & $.491^{* *}$ & $.541^{* *}$ \\
\hline & KM8 & $.357^{* *}$ & $.390^{* *}$ & $.513^{* *}$ & $.489^{* *}$ & $.481^{* *}$ & $.619^{* *}$ & $.470^{* *}$ & $.545^{* *}$ \\
\hline & KM9 & $.281^{* *}$ & $.467^{* *}$ & $.456^{* *}$ & $.523^{* *}$ & $.578^{* *}$ & $.505^{* *}$ & $.524^{* *}$ & $.545^{* *}$ \\
\hline
\end{tabular}

Note: ${ }^{\star}$ Author's research results.

\section{Discussion}

\subsection{Correlation analysis results (checking hypothesis $\mathrm{H1}$ )}

Knowledge management has a statistically significant, positive and strong impact on financial perfoormance (Table 1). Therefore, based on this, hypothesis H1 is confirmed. Results concerning this question are consequent with the majority of existing researches (Mageswari et al., 2017; Razzaq et al., 2019; Najmi et al., 2018; Chen \& Huang, 2009; Lee et al., 2008; Darroch, 2005). 
When it comes to the knowledge management dimensions, KM9 - Competitive Advantage; KM7 - Knowledge Application Processes; and KM8 - Knowledge Protection Processes have the strongest impact on financial performance. Based on this, it can be argued that the dimensions which involve the practical and market aspects of knowledge management, as well as those which are visible, not only internally but also externally when an enterprise enters a market, have the biggest impact on financial performance. Then, through the application and protection of knowledge, clear competitive advantage is achieved and direct benefits from knowledge management are obtained. These dimensions accumulate and support the efforts of the other dimensions and directly influence financial performance.

The remaining components of KM are more internally oriented and are merely the preparation for the main benefits of knowledge management. It should be noted that there is a general similarity with the results of other researches concerning this question. Therefore, the following researches confirm the correlation between KM, competitiveness and financial performance (Echeverry et al., 2019; Lopez et al., 2005; Byrd \& Turner, 2001; Zebal et al., 2019), the impact of knowledge application processes on financial performance (Lee et al., 2005; Chen \& Huang, 2009; Darroch, 2005; Abbas \& Sağsan, 2019; Imran et al., 2017; Zack et al., 2009), as well as the impact of knowledge protection process on financial performance (Huang et al., 2019).

Furthermore, regarding the dimensions of KM, the KM2 - Organizational Culture and KM1 - Organizational Structure dimensions were found to have the weakest influence on financial performance. Establishing an organizational structure supporting KM, as well as adopting an organizational culture which values knowledge and learning, is certainly very important for the systematic application of knowledge management. It also plays an important role in future activities and success in the implementation process of knowledge management. However, these dimensions are the basis, and specific effects in the form of raising financial performance are only achieved through the process of applying knowledge and gaining competitiveness through such knowledge. In a practical sense, favourable organizational structure and culture create a solid foundation for the concept of knowledge management, but do not bring direct benefits when it comes to financial performance. These benefits are obtained in the market. The situation is similar with the KM3 - T-shaped skills - Human Resources dimension, which was also found to have a lower impact on financial performance. The existence of human resources with valuable skills, abilities, specialties and knowledge is certainly important, but is not necessarily sufficient as such potential has yet to be used on the market and to achieve concrete results (in the form of improved financial performance). It is important to note that the aforementioned knowledge management dimensions (KM1, KM2 and KM3) also have a statistically significant and positive impact on financial performance. However, this impact is slightly smaller compared to the impact of the other observed dimensions of KM.

Further, it was found that the knowledge management dimensions have the strongest influence on the FP - Financial Performance dimension which integrates the seven financial performance items. This indicates that knowledge management has the strongest influence on the amalgamated financial performance items. Similarly, the knowledge management dimensions have a strong influence on FP4 - Sales Growth; followed by FP6 - Asset Growth; FP3 - 
Market Share; and FP5 - Competitive Status. Knowledge management exerts a strong impact on the market aspects of the business, but also the increase of fixed assets. On the other hand, knowledge management has the weakest impact on FP1 - Productivity; FP2 - Profitability; and FP7 - Salaries. These items are influenced more by the type of business activity, and the situation in the branch of a specific enterprise. The FP7 - Salaries item significantly depends on the organization's business policy and the attitude of the management to this issue.

\subsection{Regression analysis results (checking hypothesis $\mathrm{H} 2$ )}

From all the knowledge management dimensions the KM9 - Competitive Advantage dimension has the strongest predictive effect, which is in line with correlation analysis results. The competitive advantage gained through knowledge management brings direct benefits to the organization on the market. Here, the company materializes a high level of knowledge management. The nature of this dimension is such that it acts externally and therefore affects the financial performance provided on the market, outside the organization. It can thus be argued that this dimension most directly improves financial performance in the organization.

The next dimension according to the strength of the predictive effect is KM8 - Knowledge Protection Processes, which is also consistent with the results of the correlation analysis. Knowledge protection ensures that there is no inappropriate use of knowledge or knowledge theft, and it makes it difficult for competitors to copy acquired knowledge. Moreover, it nurtures individuals who possess knowledge. All of this is very important for ensuring long-term business performance, which ultimately results in improved financial performance.

The dimensions KM7 - Knowledge Application Processes; KM5 - Knowledge Acquisition Processes; and KM1 - Organizational Structure also have predictive effects. A slight deviation from the results of the correlation analysis exists in the predictive effect of the KM1 - Organizational Structure dimension. However, this predictive effect occurs with the FP1 - Productivity item, with which the KM1 - Organizational Structure dimension already has a very high correlation $\left(0.567^{* *}\right.$, Table 1$)$. In addition, it is clear that a well-established organizational structure increases productivity. The other dimensions of knowledge management do not have any predictive effects. Considering the individual dependent variables, the following predictive effects are observed:

- Item: FP1 - Productivity. High levels of KM1 - Organizational Structure lead to increased productivity. Any well-designed organizational structure, regardless of whether or not the structure is tailored to knowledge management, will certainly create the conditions for increasing productivity.

- Item FP2 Profitability. High levels of KM9 - Competitive Advantage increase profitability. Acquiring competitive advantage creates the conditions for the inflow of revenue, making the organization profitable.

- Item FP3 - Market Share. High levels of KM5 - Knowledge Acquisition Processes increase market share: The knowledge acquisition process involves acquiring knowledge on new products/services and competitors, which in turn contributes to a market share increase.

- Item FP4 Aim - Sales Growth. High levels of KM7 - Knowledge Application Processes increase sales growth: Knowledge application involves the use of knowledge in a 
practical and external sense, so that knowledge becomes visible on the market, thus resulting in sales growth.

- Item FP5 - Competitive Status. High levels of KM9 - Competitive Advantage increase competitiveness: This is a very logical relationship.

- Item FP6 - Asset Growth. High levels of KM8 - Knowledge Protection Processes increase the growth of fixed assets: The relationship between investing in knowledge protection and fixed assets means that the organization takes care of its resources, both intangible and material.

- Item FP7 - Salaries. High levels of KM9 High - Competitive Advantage increase employee salaries. Increased competitiveness not only increases revenue for the organization, but also guarantees its stability and a more secure future on the market. In turn, the management of the organization is more likely to invest in employees' salaries.

- Dimension FP - Financial Performance. High levels of KM1 - Organizational Structure; KM8 - Knowledge Protection Processes; and KM9 - Competitive Advantage increase overall financial performance.

- The FP - Financial Performance dimension integrates individual financial performance metrics, thus the predictive effects are also integrated. As predictors, three knowledge management dimensions had the strongest predictive effects on individual items. Overall, it can be argued that knowledge management affects financial performance as follows: financial performance increases when an effective organizational structure (KM1 - Organizational Structure) is in place; when an organization takes care of its future by protecting its knowledge and human resources (KM8 - Knowledge Protection Processes); and when it manages to materialize the acquired knowledge in the form of competitive advantage (KM9 - Competitive Advantage).

The previous discussion shows that each financial performance item is subject to the predictive action of only one knowledge management dimension. Therefore, for each financial performance item, a predictive effect is assumed by one dimension of knowledge management. However, the difference lies with the dimension FP - Financial Performance, precisely because it integrates the predictive effects of individual items, where the most "powerful" items dominate.

The corrected determination indexes $\mathrm{R}^{2}$ have high values $(0.233-0.336)$. Based on this and the previously discussed results of the regression analysis, KM dimensions have statistically significant predictive effects on financial performance. Hence, the second hypothesis, $\mathrm{H} 2$, is confirmed.

\subsection{The moderating effect of the National Origin of companies (answer to research question RQ1)}

National Origin of the company as a moderator exists only in a small number of cases (three cases) and even in these cases that effect is weak. This answers the first research question RQ1. Overall, this study shows that KM has a somewhat greater impact on financial performance in foreign companies that operate in Serbia than in domestic (Serbian) companies. It should be noted that all the correlations in both groups are statistically significant and positive. 
When it comes to foreign companies, the KM6 - Knowledge Conversion Processes dimension has a statistically significant and strong influence on FP1 - Productivity. The knowledge conversion process involves knowledge filtering (recognizing what is significant); transferring knowledge to and between employees and acquiring knowledge from employees; organizing knowledge; and replacing outdated knowledge. These activities can contribute to higher productivity. Foreign companies are likely to pay more attention to knowledge conversion processes, so this reflects more on productivity in such companies when compared to domestic enterprises.

Further, in foreign companies, the dimensions KM1 - Organizational Structure and KM2 - Organizational Culture have a statistically significant and stronger influence on FP6 - Asset Growth when compared to domestic enterprises. These two knowledge management dimensions can be viewed as indicators of a systematic approach to knowledge management on an organizational level and a sign that knowledge management is highly valued in the organization. With such an attitude and approach, it is very likely that the organization takes care of its fixed assets and that it invests in the future. Foreign companies are probably more aware of the need to invest in fixed assets, and this notion is embedded in both their organizational structure and organizational culture.

\subsection{Enterprise Size as a moderator (answer to research question RQ2)}

The moderating effect of the Enterprise Size moderator is present in several cases and the strength of this effect is moderate. This answers the second research question - RQ2. The correlations are stronger for medium and large enterprises (with one exception, which will be explained below). Knowledge management has a slightly greater impact on financial performance in medium and large enterprises than in small enterprises. However, it should be noted that all the correlations in both groups are positive and statistically significant. Existing studies in this domain (Wong, 2005; Liu \& Ren, 2019; Lee et al., 2008) indicate that the very concept of knowledge management is better suited for large systems. Hence, the stronger effect of knowledge management in larger organizations. Therefore, it is suggested that SMEs adapt their knowledge management infrastructure in accordance with their needs and business conditions.

The biggest difference in terms of the impact of knowledge management is present for the FP6 Asset Growth item. Here, knowledge management has a statistically significant and stronger influence on the FP6 - Asset Growth item. Larger companies often rely on their size and resources in the competitive struggle. This is why larger businesses apply knowledge management with the goal of improving their already strong business parameters. In addition, large companies usually have more opportunities to invest in their fixed assets and thus enhance resources.

There is also a significant difference in influence when it comes to FP1 - Productivity. The dimensions KM5 - Knowledge Acquisition processes and KM6 - Knowledge Conversion Processes have a greater impact on productivity in medium and large enterprises, while the KM3 - T-shaped skills - Human Resources dimension has a larger impact on productivity in small enterprises. System processes on the organizational level, such as the acquisition and 
conversion of knowledge, have a comprehensive effect in larger organizational systems and are more prominent than in smaller enterprises. On the other hand, the knowledge, skills and abilities of human resources may make a greater contribution to productivity in smaller enterprises. Therefore, learning and acquiring knowledge on the individual level is more pronounced in smaller enterprises. Thus, the relationship between the KM3 dimension and the FP1 item is an exception to the model, where the impact is stronger in small businesses.

Other relations where the knowledge management dimensions have a statistically significant and stronger influence in medium and large enterprises are also present. The relationship between the KM1 - Organizational Structure dimension and the FP3 - Market Share item, as well as that between the KM4 - Information Technology dimension and the FP7 - Salaries item, were found to be stronger in medium and large enterprises. Thus, in larger enterprises, an organizational culture based on knowledge management can increase market share, while information technology focused on knowledge management may serve to increase employee earnings.

When observing the knowledge management dimensions, it should be noted that the highest number of moderating effects are related to the dimension KM6 - Knowledge Conversion Processes. In smaller companies, information is transferred faster and more easily, and this is also reflected in knowledge conversion processes, which do not need to be as present or developed. Large enterprises, on the other hand, are likely to have more opportunities, time, and needs when it comes to paying attention to knowledge conversion. For these reasons, knowledge conversion processes have a significantly stronger impact on financial performance in larger companies.

\section{Conclusions}

This paper presents a detailed analysis of the effects of the individual dimensions of knowledge management on individual financial performance items. Two moderators were also analyzed. The significance and originality of this paper lies in the main research setting and the approach to analyzing the obtained results. Both hypotheses were confirmed and both research questions were answered.

All correlations between the analyzed dimensions of knowledge management and the financial performance items, as well as the financial performance dimension, are statistically significant and positive. The following dimensions have the strongest impact on financial performance: KM9 - Competitive Advantage, followed by KM7 - Knowledge Application Processes, and KM8 - Knowledge Protection Processes. Therefore, financial performance is most influenced by those dimensions related to the effects of knowledge management in terms of its application and protection, and the acquisition of competitive ability. These dimensions act externally, on the market, and directly affect financial performance. The other dimensions are more internally oriented and represent the basis for the effective application of knowledge and achieving positive business effects.

The knowledge management dimensions have the strongest influence on the FP dimension, and then on the financial performance items: FP4 - Sales Growth, FP6 - Asset Growth, FP3 - Market Share, and FP5 - Competitive Status. Therefore, it can be argued that 
knowledge management strongly influences not only the market aspects of the business, but also the growth of fixed assets.

The regression analysis showed that the KM9 - Competitive Advantage dimension has the strongest predictive effect, which is consistent with the results of the correlation analysis. Similarly, predictive effects were found for the KM8 - Knowledge Protection Processes; KM7 - Knowledge Application Processes; KM5 - Knowledge Acquisition Processes; and KM1 - Organizational Structure dimensions.

The moderating effect of National Origin of Enterprises exists in a small number of cases, and is manifested by the fact that the correlations are stronger for foreign companies (operating in Serbia). Foreign companies pay slightly more attention to knowledge conversion processes and invest more in fixed assets. The moderating effect of Enterprise Size exists in a number of cases, where the correlations are stronger in medium and large enterprises. This is most evident for the FP6 - Asset Growth and FP1 - Productivity items. The KM5 - Knowledge Acquisition Processes and KM6 - Knowledge Conversion Processes dimensions have a greater impact on productivity in medium and large enterprises, while the KM3 - T-shaped skills - Human Resources dimension has a larger impact on productivity in small enterprises.

It is clear that a high level of knowledge management has a positive impact on business performance, quality, productivity and competitiveness. The results obtained in this paper are consistent with the majority of other findings in this domain. This paper indicates that knowledge management has the greatest effect on financial performance in conditions where an effective organizational structure is established; where the organization protects its knowledge; and where the organization manages to materialize the acquired knowledge in both the process of knowledge application and that of gaining competitive ability through knowledge. These findings can also be considered as general recommendations for top management in Serbian enterprises, when it comes to increasing the level of financial performance in enterprises through knowledge management.

In addition to these general recommendations, it is important to define more practical and precise improvement strategies in accordance with the obtained results. These exit strategies, for improving KM in order to increase financial performance levels, are presented through six recommendations and guidelines for managers or practitioners. These are:

1. Establishing a structure that facilitates the identification and creating new knowledge, also the transfer of new knowledge among sectors.

2. Implement and apply standardized reward systems for knowledge exchange within work, training and learning.

3. Apply information technology for remote learning. Enable employees to learn both individually and in groups, as well as to map the locations of certain types of knowledge.

4. Implement and apply processes for acquiring knowledge about customers and suppliers.

5. Implement and apply processes for using knowledge in the development of new products and/or services. 
6. Implement and apply processes for protecting knowledge so as to avoid inappropriate use inside and outside the organization, as well as to create awareness of the importance of knowledge security.

After the implementation of the above recommendations and guidelines, it is necessary to reassess the financial performance levels. Therefore, analysis and evaluation of the knowledge management effects on the financial performance dimension is conducted. Based on this analysis, it is necessary to re-evaluate which recommendations and guidelines should be re-implemented and improved.

The basic limitation lies in the fact that the acquired results and the suggested recommendations are valid for Serbian companies. However, it can be assumed with a high level of certainty that similar relationships exist in other countries, especially in those with similar economic and social development, as well as a similar national culture. For future research it is recommended to conduct a meta-analysis of previous studies in this domain. Additionally, these meta-analyses should categorize specific industries and years of publication. Such research could provide a thorough overview on the dynamics of knowledge management effect on financial performance in enterprises.

\section{References}

Abbas, J., \& Sağsan, M. (2019). Impact of knowledge management practices on green innovation and corporate sustainable development: A structural analysis. Journal of Cleaner Production, 229, 611620. https://doi.org/10.1016/j.jclepro.2019.05.024

Abdi, K., Mardani, A., Senin, A. A., Tupenaite, L., Naimaviciene, J., Kanapeckiene, L., \& Kutut, V. (2018). The effect of knowledge management, organizational culture and organizational learning on innovation in automotive industry. Journal of Business Economics and Management, 19(1), 1-19. https://doi.org/10.3846/jbem.2018.1477

Allameh, S. M. (2018). Antecedents and consequences of intellectual capital: The role of social capital, knowledge sharing and innovation. Journal of Intellectual Capital, 19(5), 858-874. https://doi.org/10.1108/JIC-05-2017-0068

American Productivity and Quality Center. (1998). Knowledge management and the learning organization: A European perspective. APQC.

Bontis, N., Dragonetti, N. C., Jacobsen, K., \& Roos, G. (1999). The knowledge toolbox: A review of the tools available to measure and manage intangible resources. European Management Journal, 17(4), 391-402. https://doi.org/10.1016/S0263-2373(99)00019-5

Byrd, T., \& Turner, D. (2001). An exploratory examination of the relationship between flexible IT infrastructure and competitive advantage. Information and Management, 39(1), 41-52. https://doi.org/10.1016/S0378-7206(01)00078-7

Chen, C., \& Huang, J. (2009). Strategic human resource practices and innovation performance - The mediating role of knowledge management capacity. Journal of Business Research, 62(1), 104-114. https://doi.org/10.1016/j.jbusres.2007.11.016

Crema, M., \& Verbano, C. (2016). Managing intellectual capital in Italian manufacturing SMEs. Creativity and Innovation Management, 25(3), 408-421. https://doi.org/10.1111/caim.12074

Dang, C., Le-Hoai, L., \& Kim, S. Y. (2018). Impact of knowledge enabling factors on organizational effectiveness in construction companies. Journal of Knowledge Management, 22(4), 759-780.

https://doi.org/10.1108/JKM-08-2016-0350 
Darroch, J. (2005). Knowledge management, innovation and firm performance. Journal of Knowledge Management, 9(3), 101-115. https://doi.org/10.1108/13673270510602809

Darroch, J., \& McNaughton, R. (2002). Examining the link between knowledge management practices and types of innovation. Journal of Intellectual Capital, 3(3), 210-222.

https://doi.org/10.1108/14691930210435570

Davenport, H. T., \& ve Prusak, L. (2000). İş dünyasında bilgi yönetimi: Kuruluşlar ellerindeki bilgiyi nasıl yönetirler? Çev. Günhan Günay. Rota Yayın. https://www.kitapyurdu.com/kitap/is-dunyasinda-bilgiyonetimi-kuruluslar-ellerindeki-bilgiyi-nasil-yonetirler/31034.htm

Dzenopoljac, V., Yaacoub, C., Elkanj, N., \& Bontis, N. (2017). Impact of intellectual capital on corporate performance: Evidence from the Arab region. Journal of Intellectual Capital, 18(4), 884-903. https://doi.org/10.1108/JIC-01-2017-0014

Echeverry, C., Herrera, O., \& Velez, A. (2019). Knowledge management from the organizational culture in call centers in Manizales. Cuadernos de Administracion, 35(63), 15-25. https://doi.org/10.25100/cdea.v35i63.6811

Fathi, S., Farahmand, S., \& Khorasani, M. (2013). Impact of intellectual capital on financial performance. International Journal of Academic Research in Economics and Management Sciences, 2(1), 6-17. https://www.researchgate.net/publication/331687713_Impact_of_intellectual_capital_on_financial_performance

Ferramosca, S., \& Ghio, A. (2018). Leveraging intellectual capital in developing countries: evidence from Kenya. Journal of Intellectual Capital, 19(3), 562-580.

https://doi.org/10.1108/JIC-11-2016-0109

Gross-Golacka, E., Kusterka-Jefmanska, M., \& Jefmanski, B. (2020). Can elements of intellectual capital improve business sustainability? The perspective of managers of SMEs in Poland. Sustainability, 12(4), 1545. https://doi.org/10.3390/su12041545

Hermawan, S., Hariyanto, W., \& Biduri, S. (2020). Intellectual capital, business performance, and competitive advantage: An empirical study for the pharmaceutical companies. QUALITY Access to Success, 21(175), 103-106.

Huang, Y., Yan, A., \& Smith, R. (2019). Methodology for the development of knowledge management on organizational performance based on employees' professional competence. Revista de Cercetare Si Interventie Sociala, 64, 85-96. https://doi.org/10.33788/rcis.64.7

Imran, M., Bilal, A., Aslam, U., \& Rahman, U. (2017). Knowledge management strategy: An organizational change prospective. Journal of Enterprise Information Management, 30(2), 335-351. https://doi.org/10.1108/JEIM-10-2015-0095

James, P. (2005). Knowledge asset management: The strategic management and knowledge management nexus [DBA thesis]. Southern Cross University. https://researchportal.scu.edu.au/esploro/outputs/ doctoral/Knowledge-asset-management--the-strategic-management-and-knowledge-managementnexus/991012821396602368

Jordão, R. V. D., \& de Almeida, V. R. (2017). Performance measurement, intellectual capital and financial sustainability. Journal of Intellectual Capital, 18(3), 643-666.

https://doi.org/10.1108/JIC-11-2016-0115

Joshi, M., Cahill, D., Sidhu, J., \& Kansal, M. (2013). Intellectual capital and financial performance: An evaluation of the Australian financial sector. Journal of Intellectual Capital, 14(2), 264-285. https://doi.org/10.1108/14691931311323887

Kianto, A., Andreeva, T., \& Pavlov, Y. (2013). The impact of intellectual capital management on company competitiveness and financial performance. Knowledge Management Research \& Practice, 11(2), 112-122. https://doi.org/10.1057/kmrp.2013.9

Kongpichayanond, P. (2009). Knowledge management for sustained competitive advantage in mergers and acquisitions. Advances in Developing Human Resources, 11(3), 375-87.

https://doi.org/10.1177/1523422309339725 
Lee, C., Ho, C., \& Chiu, Y. (2008). The impact of knowledge management enablers on non-financial performance in small and medium enterprises. International Journal of Technology Management, 43(1-3), 266-283. https://doi.org/10.1504/IJTM.2008.019419

Lee, I. A. (2008). Relationship between the use of information technology and performances of human resourses management [PhD Thesis]. Alliant International University. San Diego, CA.

Lee, K., Lee, S., \& Kang, I. (2005). KMPI: Measuring knowledge management performance. Information \& Management, 43(3), 469-482. https://doi.org/10.1016/j.im.2004.02.003

Liu, G., \& Ren, H. (2019). Organizational learning and job satisfaction of trainee auditors: A case study of Chinese CPA firms. Accounting Research Journal, 32(2), 70-87. https://doi.org/10.1108/ARJ-04-2016-0049

Lopez, S., Peón, J., \& Ordás, C. (2005). Organizational learning as a determining factor in business performance. The Learning Organization, 12(3), 227-245. https://doi.org/10.1108/09696470510592494

Madella, A., Bayle, E., \& Tome, J.-L. (2005). The organizational performance of national swimming federations in mediterranean countries: A comparative approach. European Journal of Sport Science, 5(4), 207-220. https://doi.org/10.1080/17461390500344644

Maditinos, D., Chatzoudes, D., Tsairidis, C., \& Theriou, G. (2011). The impact of intellectual capital on firms' market value and financial performance. Journal of Intellectual Capital, 12(1), 132-151. https://doi.org/10.1108/14691931111097944

Mageswari, S., Sivasubramanian, R., \& Dath, T. (2017). A comprehensive analysis of knowledge management in Indian manufacturing companies. Journal of Manufacturing Technology Management, 28(4), 506-530. https://doi.org/10.1108/JMTM-08-2016-0107

Martin, J. (1998). The knowledge era. DM Review Magazine.

Massa, S., \& Testa, S. (2009). A knowledge management approach to organizational competitive advantage: Evidence from the food sector. European Management Journal, 27(2), 129-141. https://doi.org/10.1016/j.emj.2008.06.005

Mondal, A., \& Ghosh, S. (2012). Intellectual capital and financial performance of Indian banks. Journal of Intellectual Capital, 13(4), 515-530. https://doi.org/10.1108/14691931211276115

Najmi, K., Kadir, A., \& Kadir, M. (2018). Mediation effect of dynamic capability in the relationship between knowledge management and strategic leadership on organizational performance accountability. International Journal of Law and Management, 60(2), 517-529. https://doi.org/10.1108/IJLMA-01-2017-0004

Nguyen, T. N. Q. (2010). Knowledge management capability and competitive advantage: An empirical study of Vietnamese enterprises [PhD thesis]. Southern Cross University. Lismore, NSW. http://citeseerx.ist.psu.edu/viewdoc/download;jsessionid=305818D05BAB4E5638D9AB6D6BCE45 $3 \mathrm{~A}$ ?doi=10.1.1.682.6586\&rep=rep1\&type $=$ pdf

Ouekouak, M. L., Ouedraogo, N. \& Mbengue, A. (2014). The mediating role of organizational capabilities in the relationship between middle managers' involvement and firm performance: A European study. European Management Journal, 32(2), 305-318. https://doi.org/10.1016/j.emj.2013.03.002

Prieto, I., \& Revilla, E. (2006). Learning capability and business performance: A non-financial and financial assessment. The Learning Organization, 13(2), 166-185. https://doi.org/10.1108/09696470610645494

Razzaq, S., Shujahat, M., Hussain, S., Nawaz, F., Wang, M., Ali, M., \& Tehseen, S. (2019). Knowledge management, organizational commitment and knowledge-worker performance: The neglected role of knowledge management in the public sector. Business Process Management Journal, 25(5), 923-947. https://doi.org/10.1108/BPMJ-03-2018-0079

Sabău Popa, D. C., Popa, D. N., Bogdan, V., \& Simut, R. (2021). Composite financial performance index prediction - a neural networks approach. Journal of Business Economics and Management, 22(2), 277-296. https://doi.org/10.3846/jbem.2021.14000 
Sanchez, V. (2018). Self-employment, knowledge and economic growth: An empirical study for Latin American countries. Contemporary Economics, 12(4), 473-484. https://www.researchgate.net/publication/330698900_Self-employment_knowledge_and_economic_growth_An_empirical_study_ for_Latin_American_countries

Schermerhorn, J. R. Jr, Hunt, J. M., \& Osborn, R. N. (2002). Organizational behavior ( $7^{\text {th }}$ ed.). Wiley.

Sharma, S., \& Dharni, K. (2017). Intellectual capital disclosures in an emerging economy: Status and trends. Journal of Intellectual Capital, 18(4), 868-883. https://doi.org/10.1108/JIC-09-2016-0092

Shockley, W. (2000). Planning for knowledge management. Quality Progress, 33(3), 57-64. https://quality-texas.org/wp-content/uploads/2014/11/Knowledge-Management.pdf

Tan, J. J., \& Litschert, R. J. (1994). Environment-strategy relationship and its performance implications: An empirical study of the Chinese electronics industry. Strategic Management Journal, 15(1), 1-20. https://doi.org/10.1002/smj.4250150102

Tonial, G., Cassol, A., Selig, P. M., \& Giugliani, E. (2019). Intellectual capital management and sustainability activities in Brazilian organizations: A case study. In F. Matos, V. Vairinhos, P. M. Selig, \& L. Edvinsson (Eds.), Intellectual capital management as a driver of sustainability (pp. 119-138). Springer. https://doi.org/10.1007/978-3-319-79051-0

Walters, D. (2002). Operations strategy. Palgrave Macmillan. https://doi.org/10.1007/978-1-4039-1446-0

Wang, D., Tsui, A. S., Zhang, Y., \& Ma, L. (2003). Employment relationships and firm performance: Evidence from an emerging economy. Journal of Organizational Behavior, 24(5), 511-535. https://doi.org/10.1002/job.213

Wang, H., Tsui, A. S., \& Xin, K. R. (2011). CEO leadership behaviors, organizational performance, and employees' attitudes. The Leadership Quarterly, 22(1), 92-105.

https://doi.org/10.1016/j.leaqua.2010.12.009

Wong, K. (2005). Critical success factors for implementing knowledge management in small and medium enterprises. Industrial Management \& Data Systems, 105(3), 261-279.

https://doi.org/10.1108/02635570510590101

Xu, J., \& Li, J. S. (2019). The impact of intellectual capital on SMEs' performance in China: Empirical evidence from non-high-tech vs. high-tech SMEs. Journal of Intellectual Capital, 20(4), 488-509. https://doi.org/10.1108/JIC-04-2018-0074

Xu, J., \& Liu, F. (2020). The impact of intellectual capital on firm performance: A modified and extended VAIC model. Journal of Competitiveness, 12(1), 161-176. https://doi.org/10.7441/joc.2010.01.10

Xu, J., \& Liu, F. (2021). Nexus between intellectual capital and financial performance: An investigation of Chinese manufacturing industry. Journal of Business Economics and Management, 22(1), 217-235. https://doi.org/10.3846/jbem.2020.13888

$\mathrm{Xu}$, J., \& Wang, B. H. (2018). Intellectual capital, financial performance and companies' sustainable growth: Evidence from the Korean manufacturing industry. Sustainability, 10(12), 4651. https://doi.org/10.3390/su10124651

Zack, M., McKeen, J., \& Singh, S. (2009). Knowledge management and organizational performance: An exploratory analysis. Journal of Knowledge Management, 13(6), 392-409. https://doi.org/10.1108/13673270910997088

Zebal, M., Ferdous, A., \& Chambers, C. (2019). An integrated model of marketing knowledge - a tacit knowledge perspective. Journal of Research in Marketing and Entrepreneurship, 21(1), 2-18. https://doi.org/10.1108/JRME-03-2018-0018 